\title{
A Rare Case Report of Primary Eosinophilic Colitis
}

\author{
Tran Thi Khanh Tuong* \\ Department of Internal Medicine, Pham Ngoc Thach University of Medicine, Vitneam \\ *Corresponding author: Tran Thi Khanh Tuong, Department of Internal Medicine, Pham Ngoc Thach University of \\ Medicine, 02 Duong Quang Trung, District 10, Ho Chi Minh city, Vietnam
}

\begin{tabular}{|c|c|}
\hline ARTICLE INFO & ABSTRACT \\
\hline Received: 幽 February 25, 2020 & \multirow{3}{*}{$\begin{array}{l}\text { Eosinophilic enterocolitis is the rarest form in primary eosinophilic gastrointestinal } \\
\text { disease (EGID) without other causes of eosinophilia. There are few described cases } \\
\text { in the literature. We reported a rare case of eosinophilic colitis, where a } 35 \text {-year-old } \\
\text { woman presented to us with chronic diarrhoea associated with abdominal pain and } \\
\text { rectal bleeding for } 6 \text { months. She had features of unspecific colitis and significant } \\
\text { eosinophilia with the colonic biopsy reported. Diarrhoea was resolved with a course } \\
\text { of corticosteroid. No complications or recurrences were reported. In conclusion, } \\
\text { Eosinophilic colitis is rarely reported. Eosinophilic colitis ethology and pathogenesis is } \\
\text { unknown. Its clinical, endoscopic and imaging features are not specific. However, this } \\
\text { could be underdiagnosed. All chronic diarrhoea cases should be offered colonoscopy } \\
\text { with biopsy to rule out Eosinophilic Colitis. }\end{array}$} \\
\hline Published: March 06, 2020 & \\
\hline $\begin{array}{l}\text { Citation: Tran Thi Khanh T. A Rare Case } \\
\text { Report of Primary Eosinophilic Colitis. } \\
\text { Biomed J Sci \& Tech Res 26(3)-2020. BJSTR. } \\
\text { MS.ID.004346. }\end{array}$ & \\
\hline
\end{tabular}

\section{Introduction}

Eosinophilic gastrointestinal disorder is characterized by eosinophilic infiltrates along the gastrointestinal tract without any other cause such as drug reactions, parasitic infections or malignancies [1]. Eosinophilic gastrointestinal disorders include eosinophilic esophagitis, eosinophilic gastroenteritis and eosinophilic colitis, with eosinophilia. acidosis is the rarest form. Most cases of primary eosinophilic colitis are idiopathic. Secondary eosinophilic infiltrates in the colon wall can be caused by a variety of causes, such as parasitic infections, medications or enteritis disease. Therefore, the diagnosis of primary eosinophilic colitis is an excluded diagnosis. This is a rare condition with an unclear pathogenetic mechanism and a poor response to treatment. There have been rarely case reports of eosinophilic colitis. To date, about 52 cases have been reported in the world [2]. We have reported a case of eosinophilic colitis in 34-year-old women successfully treated with corticosteroids. Our report aims to raise clinicians' awareness of eosinophilic colitis that may appear as chronic diarrhoea and require corticosteroid treatment.

\section{Case Report}

A 34-year-old female patients with a history of diarrhoea who had been treated for more than 6 months but did not reduce, went to Ho Chi Minh City University of Medicine Hospital in March
2019. Patients with loose stool, 4-6 times daily with abdominal cramps and occasional red bloody stools. Patients without fever, losing about $2 \mathrm{~kg}$ in 6 months, without a skin rash. The episodes of diarrhoea are not related to food. The patients had no history of drug and food allergy. The patient has not had colonoscopy and stool tests. Patients previously diagnosed with unexplained colitis and amoebic dysentery, were treated with metronidazole, ciprofloxacin, diarrhoea medications such as Imodium and antispasmodics, but the symptoms did not improve. The patient's family history has not been reported to have similar pathology. Examining patients who have not detected abnormal symptoms. We indicated to perform some blood tests, stool, abdominal ultrasound and colonoscopy. Subclinical results of patients are as follows:

a) Hemoglobin $12.2 \mathrm{~g} / \mathrm{dL}$ với haematocrit of $39.4 \%$; White blood 9500/mm3 (neutrophils: 64\%; eosinophils 7\% with absolute count: $0.67 \times 109 / \mathrm{L}$, Lymphocytes $17 \%$ ) and platelet count $261,000 / \mathrm{mm} 3$.

b) Normal erythrocyte sedimentation rate.

c) IgE concentration within normal limits

d) Hepatic Biochemistry test, kidney function within normal limits.

e) Normal thyroid function.

f) HIV test was negative. 
g) Stool culture was negative, hidden blood in stool positive.

h) Abdominal ultrasound only records mild fatty liver.

Endoscopy in most eosinophilic colitis shows normal colon mucosa, which helps distinguish it from other forms of colitis. Nonspecific endoscopy results, such as mucosal edema, regional hyperaemia, and other lesions such as granular mucosa and aphthous ulcers can be seen, although these features are uncommon and not should rely on for diagnosis [3]. Results of biopsy of the colon mucosa show that the colon lining with normal gland or benign hyperplasia with permeability of chronic inflammatory cells in the stroma, there are many eosinophils (Figure 1).

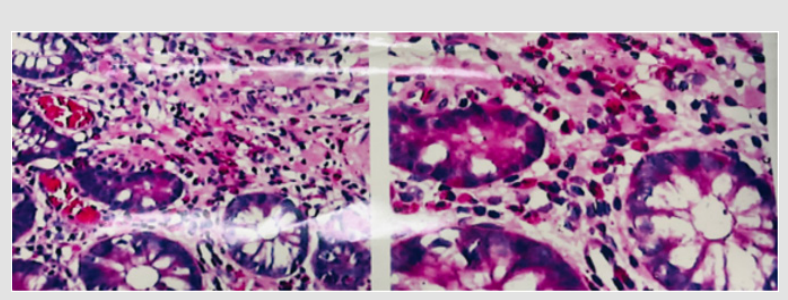

Figure 1: Histopathological Imaging of Colon Biopsy Showed Eosinophilic Infiltrate.

The patients were diagnosed with primary eosinophilic colitis. Patients were treated with $40 \mathrm{mg} /$ day prednisone for 4 weeks and then gradually reduced for 8 weeks. Diarrhoea and abdominal pain improved after the first 2 weeks of prednisone treatment. Gastrointestinal symptoms improved completely after 8 weeks of treatment, patients with abdominal pain, 1 time / day, stools, no more blood and peripheral eosinophilia returned to normal. After stopping prednisone 6 months, patients do not have relapse symptoms of gastrointestinal, stool examination normal.

\section{Discussion}

The pathophysiology of eosinophilic colitis is still unknown. Primary eosinophilic colitis may be due to an Th2 lymphoidmediated immune response in adults. IL-3, IL-5 and IL-13 and granulocyte macrophage stimulation factor (GM-CSF) may play an important role in eosinophil infiltrates into colon tissue [1]. The diagnosis of primary eosinophilic colitis is a diagnosis that excludes secondary causes with three signs: peripheral eosinophilia, eosinophil infiltrates in the colon and chronic diarrhoea [4]. Our patients met diagnostic criteria with chronic diarrhoea, peripheral eosinophilia, and histopathological findings of dense eosinophilia in the colon. Diarrhoea symptoms and eosinophilia improved with corticosteroids. The patient was clinically relieved and did not relapse despite discontinuation of corticosteroids for 6 months. Eosinophilic colitis in adults tends to be chronic. There were no randomized controlled trials in the treatment of eosinophilia, all data drawn from case reports and small cases [5]. There is only unique evidence associated with the use of montelukast in eosinophilic duodenitis [6].

Currently, the treatment for primary eosinophilic colitis is primarily based on case reports and expert opinion. There are no guidelines for the treatment of primary eosinophilia. In general, treatment is based on the presence and stability of symptoms. Dietary changes are often ineffective in adults. Corticosteroids are the most effective symptom control tool, helpful in most cases. The efficacy of corticosteroids for eosinophilic disorders is largely mediated by inhibiting eosinophil growth factors such as IL-3, IL-5 and GM-CSF [7]. The drug is often used in the same doses as those used for inflammatory bowel disease and localized budesonide can avoid systemic side effects. Corticosteroid treatment is usually recommended, in which most patients will respond within two weeks at a dose of 20-40mg per day. Although, doses higher than $0.5-1 \mathrm{mg} / \mathrm{kg} /$ day have also been noted in some reports [8].

This was also demonstrated by our patients, who responded after 2 weeks of $40 \mathrm{mg} /$ day corticosteroid therapy. The corticosteroid is thought to inhibit the growth of eosinophils. Recurrence of the disease may be frequent, so the patient may be dependent on corticosteroid. In addition, secondary causes of eosinophilic colitis should be excluded as corticosteroid therapy can exacerbate a number of diseases. Immunomodulators such as azathioprine and 6-mercillinurine may be helpful in severe and resistant cases. Other drugs include leukotriene receptor antagonists (montelukast), antihistamines and mast cell stabilizers (ketotifen, sodium cromoglicate), biological substances (omalizumab, mepolizumab) and IL-4 inhibitors. Surgery is indicated only if intestinal obstruction or perforation. There is a tendency to use biological agents in clinical development to treat gastrointestinal disorders due to primary eosinophilia.

\section{References}

1. Alfadda AA, Storr MA, Shaffer EA (2011) Eosinophilic colitis: epidemiology, clinical features, and current management. Therap Adv Gastroenterol 4(5): 301-309.

2. Díaz Del Arco C, Taxonera C, Olivares D, Fernandez Acenero MJ (2018) Eosinophilic colitis: Case series and literature review. Pathol Res Pract 214(1): 100-104.

3. Turner KO, Sinkre RA, Neumann WL, Genta RM (2017) Primary Colonic Eosinophilia and Eosinophilic Colitis in Adults. Am J Surg Pathol 41(2): 225-33.

4. Inamura H, Kashiwase Y, Morioka J, Suzuki K, Igarashi Y, et al. (2006) Accumulation of mast cells in the interstitium of eosinophilic colitis. Allergol immunopathologia 34(5) :228-230.

5. Okpara N, Asward B, Baffy G (2009) Eosinophilic colitis. World J Gastroenterol 15(24): 2975-2979.

6. Gaertner W.B, Macdonald J E, Kwaan M R, Shepela C, Madoff R, et al. (2011) Eosinophilic colitis: university of Minnesota experience and literature review. Gastroenterol Res Pract 2011: 857508.

7. Giovanna Impellizzeria, G Marasco, Leonardo Henry Eusebia, Salfi N, Bazzoli F, et al. (2019) Eosinophilic colitis: A clinical review. Digestive and Liver Disease 51(6): 769-773.

8. Zhang M, Li Y (2017) Eosinophilic gastroenteritis: A state-of-the-art review. J Gastroenterol Hepatol 32(1): 64-72. 


\section{ISSN: 2574-1241}

DOI: 10.26717/BJSTR.2020.26.004346

Tran Thi Khanh Tuong. Biomed J Sci \& Tech Res

(c) (P) This work is licensed under Creative BY Commons Attribution 4.0 License

Submission Link: https://biomedres.us/submit-manuscript.php

$\begin{array}{ll}\text { BIOMEDICAL } & \text { Assets of Publishing with us } \\ \text { RESEARCHES } & \text { - Global archiving of articles } \\ \text { - Immediate, unrestricted online access } \\ \text { - Rigorous Peer Review Process } \\ \text { https://biomedres.us/ }\end{array}$

